Jurnal Keperawatan Silampari

Volume 5, Nomor 1, Desember 2021

e-ISSN: 2581-1975

p-ISSN: 2597-7482

DOI: https://doi.org/10.31539/jks.v5i1.2966

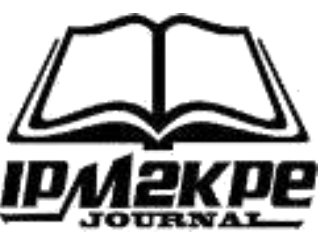

\title{
METODE SPEAK UP UNTUK MENINGKATKAN INTERPROFESSIONAL COLLABORATION PRACTICE
}

\author{
Yuliana $^{1}$, Rr. Tutik Sri Hariyati², La Ode Abdul Rahman ${ }^{3}$, \\ Cori Tri Suryani ${ }^{4}$, Herawani Azis ${ }^{5}$ \\ Universitas Indonesia ${ }^{1,2}$ \\ Rumah Sakit Umum Pusat Nasional Dr. Cipto Mangunkusumo Jakarta ${ }^{3}$ \\ Persatuan Perawat Nasional Indonesia ${ }^{4,5}$ \\ yulianasumakul@gmail.com ${ }^{1}$
}

\begin{abstract}
ABSTRAK
Penelitian ini bertujuan untuk mengidentifikasi permasalahan dan menyusun strategi improvement perawat untuk speak up dalam IPCP. Metode yang digunakan adalah program perbaikan berbasis pengembangan inovasi dengan pendekatan pilot project. Hasil penelitian menunjukkan bahwa karakteristik responden survey kepuasan perawat dalam IPCP yang dilakukan saat identifikasi masalah adalah lebih banyak perawat yang berjenis kelamin perempuan $(91 \%)$ dari pada perawat laki-laki $(9,3 \%)$, usia responden terbayak adalah antara 21 - 30 tahun (44\%), dan usia $31-40$ tahun (33\%) atau usia produktif. Tingkat pendidikan terbanyak responden adalah D3 (83\%), yang kedua Ners (23\%). Level kompetensi responden untuk PK I (25\%), PK II (32\%), PK III (45\%) dan PK IV (4\%). Jabatan responden yang turut berpartisipasi dalam survey ini terbanyak adalah Perawat Asosiate (PA) sebesar 91\% dan Perawat Primer (PP)14\%. Simpulan, metode speak up dapat meningkatkan pelayanan keperawatan, citra profesi keperawatan serta tercapainya keselamatan pasien.
\end{abstract}

Kata Kunci: Keselamatan Pasien, Praktik kolaborasi Interprofesional, Speak Up

\section{ABSTRACT}

This study aims to identify problems and develop nurse improvement strategies to speak up in IPCP. The method used is an improvement program based on innovation development with a pilot project approach. The results showed that the characteristics of the respondents in the survey of nurse satisfaction in IPCP conducted during problem identification were that there were more female nurses (91\%) than male nurses $(9.3 \%)$, the age of the most respondents was between 21-30 years. (44\%), and age $31-40$ years (33\%) or productive age. The education level of most respondents is D3 (83\%), the second is Nurses (23\%). Respondent's competency level for PK I (25\%), PK II (32\%), PK III (45\%), and PK IV (4\%). Most of the respondents who participated in this survey were Associate Nurse (PA) at $91 \%$ and Primary Nurse (PP) at 14\%. In conclusion, the speak-up method can improve nursing services, the image of the nursing profession, and the achievement of patient safety.

Keywords: Patient Safety, Interprofessional Collaborative Practice, Speak Up 


\section{PENDAHULUAN}

Pelayanan kesehatan terjadi pergeseran paradigma asuhan keperawatan yang awalnya medical centered care menjadi patient centered care, untuk itu Interprofesional Colaborative Practice (IPCP) sangatlah penting (Edgman-Levitan \& Schoenbaum, 2021). Karena permasalahan pasien yang kompleks tidak dapat ditangani hanya oleh satu profesi medis, melainkan harus melibatkan berbagai profesi. Interprofessional calaboration adalah kerjasama antara profesi kesehatan dengan latar pendidikan berbeda menjadi satu tim, berkolaborasi untuk meningkatkan kualitas pelayanan kesehatan yang efektif. Praktik kolaborasi bukan hanya diperlukan demi keselamatan pasien, tetapi juga untuk meningkatkan kepuasan profesi pemberi asuhan serta terciptanya mutu pelayanan kesehatan yang baik (Baik \& Zierler, 2019; Bursiek et al., 2020; James-Scotter et al., 2019).

Ada hubungan yang signifikan antara lingkungan kerja rumah sakit dengan karakteristik perawat. Penelitian menunjukkan bahwa lingkungan kerja rumah sakit dan karakteristik perawat seperti: lama kerja, pendidikan dan pelatihan yang didapatkan mempengaruhi keselamatan pasien (Faridah et al., 2021). Kekuatan dalam penerapan budaya keselamatan pasien dalam praktik keperawatan adalah kerja tim dalam unit, pembelajaran organisasi dan perbaikan berkelanjutan, dukungan manajemen rumah sakit untuk keselamatan pasien dan frekuensi kejadian yang dilaporkan. Sedangkan kelemahan adalah asumsi tentang keselamatan pasien, serah terima dan pemindahan, komunikasi terbuka, staf, respon non-hukuman terhadap kesalahan dan kerja tim lintas unit rumah sakit (Faridah et al., 2021).

Speak up penting untuk keselamatan pasien, tetapi profesional perawatan kesehatan sering ragu untuk menyuarakan keprihatinan mereka. Manajer keperawatan memiliki peran penting dalam mempengaruhi staf perawat untuk speak up $(\mathrm{Hu} \&$ Broome, 2020). Namun, pemahaman yang baik tentang hubungan antara perilaku manajer dan persepsi karyawan tentang apakah speak up itu aman dan bermanfaat masih kurang (Etchegaray et al., 2020; Lee et al., 2021). Hasil penelitian menunjukkan bahwa memberikan dukungan kepada perawat sehingga perawat merasakan pentingnya komitmen dari manajemen keselamatan dan merasa lebih aman untuk mengambil risiko interpersonal serta lebih bersedia untuk speak up tentang masalah keselamatan pasien (Alingh et al., 2019; Gunawan \& Hariyati, 2019; Wei et al., 2020).

Speak up mengacu pada peningkatan perhatian profesional perawatan kesehatan untuk kepentingan kualitas pelayanan dan keselamatan pasien (Palatnik, 2016). Ketika karyawan tidak angkat bicara tentang masalah, organisasi kehilangan kesempatan untuk peningkatan dan pembelajaran (Levine et al., 2020). Untuk itu organisasi perlu menghapus hambatan untuk speak up, seperti adanya stereotip, sebab ada hubungan antara stereotip dan praktek kolaboratif antarprofesional, dan stereotip berbeda di kalangan profesional kesehatan itu akan menyebabkan kesulitan dalam praktik kolaboratif di rumah sakit (Cole et al., 2019; Sari et al., 2018). Dimana penelitian menunjukkan bahwa kegagalan untuk speak up tidak terbatas pada pekerjaan tertentu tetapi terjadi lintas pekerjaan, termasuk kekhawatiran tentang status hierarki yang memimpin beberapa profesional perawatan kesehatan, yang mempertanyakan kemampuan mereka untuk berbicara, tetapi perawat lebih mungkin merasakan kemampuan berbicara setelah menerima intervensi pendidikan tentang speak up (Levine et al., 2020). 
Sebagai advokat, perawat yang mengambil tindakan untuk berbicara untuk pasien mereka memiliki identitas diri yang positif dan merasa aman serta bertanggungjawab kepada pasien mereka. Sebaliknya, seperti kelompok tertindas perawat menjadi putus asa untuk berbicara saat mengalami tekanan sosial atau ketika mereka kurang percaya diri. Perbedaan generasi juga memengaruhi cara perawat berkomunikasi pada saat observasi tampak bahwa speak up bukan sebuah budaya yang nyaman dilakukan oleh perawat, orang Asia memiliki keraguan untuk menyuarakan apa yang didapatkannya (Lee et al., 2021; Etchegaray et al., 2020).

Kompetensi interprofesional menurut Interprofessional Education Collaboration (Interprofessional Education Collaborative Expert Panel, 2011), melibatkan beberapa domain, termasuk etika dan nilai, peran dan tanggung jawab, dan komunikasi interprofesional dan kerja tim. Dalam interkolaborasi praktis ini memiliki elemenelemen antara lain: responsibility, accountability, coordination, communication, cooperation, assertiveness, autonomy, and mutual trust and respect. Semua Profesi Pemberi Asuhan (PPA) harus menjalankan elemen-eleman tersebut. Terutama dalam hal komunikasi, dalam IPCP komunikasi yang digunakan adalah komunikasi efektif (Ridar \& Santoso, 2018). Berdasarkan data dari WHO, 70-80\% kesalahan dalam pelayanan kesehatan disebabkan oleh buruknya komunikasi dan pemahaman di dalam tim (World Health Organisation, 2017).

Praktik kolaboratif dibagi menjadi tiga, yaitu kemitraan/pengambilan keputusan, kerjasama dan koordinasi yang didukung oleh perawat, dokter, ahli gizi, dan apoteker yang bekerja secara tim untuk mencapai tujuan organisasi, ketiga komponen tersebut sangat penting dalam praktik kolaboratif. Jika kemitraan dan pengambilan keputusan bersama dilaksanakan dengan baik, kemudian pilihan perawatan kesehatan untuk pasien, negosiasi antara profesional kesehatan dan tim kolaboratif keterampilan akan meningkat (Sari et al., 2018).

Penerapan IPC dibagi 4 dimensi dalam Assessment of Interprofessional Team Collaboration Scale (AITCS) meliputi partnerships, cooperation, coordination dan shared decision making (Orchard et al., 2018; Sari et al., 2018; Yusra et al., 2019). Partnerships akan efektif jika terjalin hubungan terbuka dan saling menghormati antar profesi untuk mencapai tujuan bersama (Wei et al., 2020). Cooperation merupakan tindakan kerja sama dengan mendengarkan dan menilai pendapat dari sudut pandang semua anggota tim IPCP (Mawarni et al., 2019; Vittadello et al., 2018). Coordination adalah adanya kegiatan saling memberikan informasi interprofesional (Rousseau et al., 2017). Shared decisionmaking merupakan pengambilan tanggungjawab bersama dengan keputusan bersama berdasarkan pendidikan dan kemampuan praktisi (Amadi, 2020; Moll et al., 2019; Verd-Aulí et al., 2021).

Pandemic COVID-19 memberi tantangan besar pada proses kolaborasi antara petugas kesehatan. Dalam penanganan pandemi setiap profesi kesehatan harus berkoordinasi dengan profesi lain untuk dapat memberikan layanan kesehatan yang aman dan berkualitas. Sehingga harus ada kondisi kerja yang kondusif dan aman secara interpersonal.Namun, tekanan kerja akibat perubahan pola kerja serta beban kerja yang tinggi mengakibatkan tingginya tingkat stress baik fisik maupun psikis. Akibatnya, secara tidak langsung, terbentuk atmosfer kerja yang tidak nyaman dan berimbas pada penurunan komunikasi assertive. Kondisi ini sangat beresiko menimbulkan konflik dalam kolaborasi interprofesi (Malawat et al., 2020). 
Dari studi wawancara didapatkan data bahwa selama pandemi tidak dijalankannya ronde bersama, hanya ada kegiatan geri-meet, tindakan kolaborasi yang dilakukan perawat belum kearah asuhan terintegrasi, hal ini akan berdampak pada kualitas asuhan keperawatan. Yang melakukan pendampingan saat dokter visit adalah Perawat Primer (PP), masih bersifat mendampingi dari pada sebagai mitra, untuk visit bersama apabila yang ikut PP senior tidak ada kendala komunikasi, karena berani berbicara berdasarkan knowledge yang dimiliki, jika ada konflik intercolaborative biasanya disebabkan oleh masalah komunikasi assertive antara dokter dan perawat. Tidak ada pengingat peran perawat untuk interkolaborasi. Kemampuan staff perawat untuk speak up saat visit bersama, audit klinis terintegrasi, riset bersama dan ronde bersama belum maksimal, masih ada perawat yang kurang percaya diri untuk speak up. Peran kepala ruang dalam interkolaborasi yaitu mengelola jika terjadi konflik, belum ada metode yang jelas untuk perawat melakukan speak up. Hal ini menjadi urgency, karena speak up untuk keselamatan pasien di antara profesional perawatan kesehatan adalah penting karena dapat berkontribusi pada pencegahan kejadian buruk pada pasien, seperti kesalahan pengobatan, prosedur bedah yang salah, dan kejadian sentinel lainnya. Untuk itu, metode speak up perawat dalam peningkatan interprofesional collaboration practice menjadi fokus penulis dalam pilot project untuk di analisis lebih dalam, dengan analisis fishbone yang menganalisa faktor penyebab dari man, money, method, material, machine dan informasi.

Tujuan dari pilot project adalah untuk mengidentifikasi dan menganalisa masalah terkait pelaksanaan interprofesional collaboration practice, dan memberikan gambaran tentang persepsi kepuasan perawat terhadap kompetensi, sikap dan praktik implementasi interkolaborasi professional dalam asuhan pasien serta memberikan penguatan kepada kepala ruang dalam melakukan pengarahan kepada staf perawat melalui metode speak up dalam praktik interkolaborasi di RS X.

\section{METODE PENELITIAN}

Program perbaikan berbasis pengembangan inovasi dengan pendekatan pilot project yang dimulai dengan identifikasi masalah menggunakan metode wawancara, telaah dokumen dan observasi dan melakukan survey dengan instrument, serta melakukan analisis masalah dengan analisis fishbone, melalui analisis man, money, method, machine dan material (5M) serta informasi (I). Setelah analisis data disusun plan of action untuk dilaksanakan program improvement untuk meningkatkan speak up perawat melalui pembuatan video dan leaflet. Program perbaikan ini dilakukan melalui pendekatan metode Kurt Lewin, yang di mulai dari unfreezing, moving, dan refreezing. Pemilihan sampel menggunakan teknik purposive kepada perawat yang ada di instalasi rawat inap RS X, dengan kriteria antara lain: perawat ruangan rawat inap (lantai 3,6 dan 8), bersedia mengisi kuesioner.

Pengumpulan data menggunakan instrument persepsi perawat tentang kepuasan terhadap kompetensi, sikap dan praktik implementasi interkolaborasi professional dalam asuhan pasien yang merupakan modifikasi dari Attitude toward Physician and Nurse Collaboration (JSAPNC), Chiba Interprofessional Competency Scale (CICS29), Assessment of Interprofessional Team Collaboration Scale (AITCS), yang terdiri dari enam variabel, yaitu kolaborasi (11 pertanyaan), koordinasi (12 pertanyaan), cooperation (5 pertanyaan), komunikasi (5 pertanyaan), reward atau pujian (5 pertanyaan), dan dukungan organisasi (12 pertanyaan). Menggunakan skala linkert 1: Sangat Tidak Setuju, 2: Tidak Setuju, 3: Ragu - ragu, 4: Setuju, 5: Sangat Setuju. 


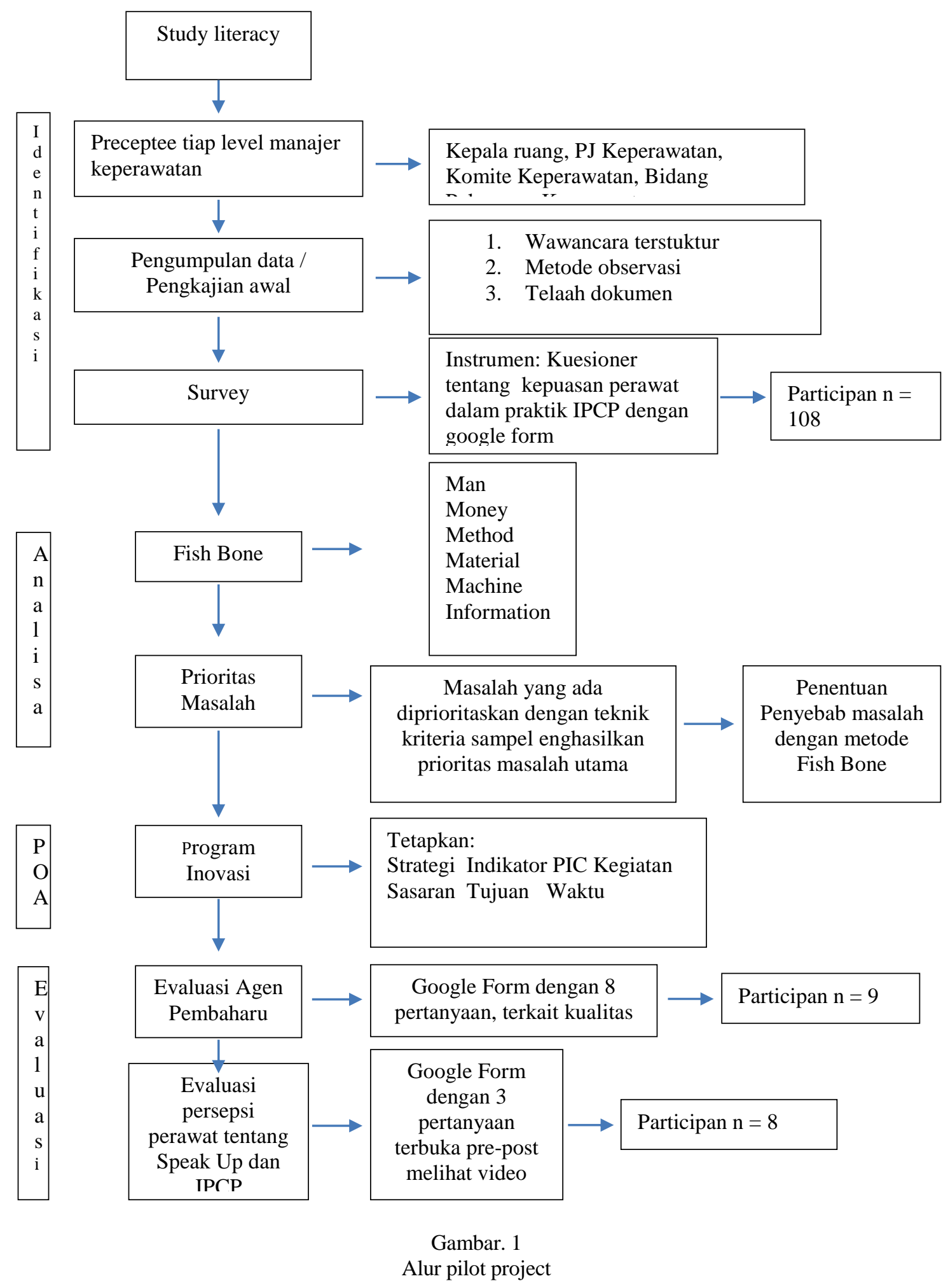

\section{HASIL PENELITIAN}

Dalam pengelolaan asuhan di ruangan rawat inap menggunakan Model Praktik Keperawatan Professional (MPKP) dimana dari pasien masuk sampai keluar ditanggungjawab oleh seorang Perawat Primer (PP) dengan dibantu oleh beberapa Perawat Associate (PA) yang dibentuk dalam satu tim. Dalam berdinas PP juga melakukan asuhan kepada pasien, kepala ruang berkoordinasi dengan PP dalam 
pelayanan sistem asuhan keperawatan (care plan), PP berdinas pagi semua, jika ada pasien baru sore atau malam PA melakukan pengkajian dan diverifikasi oleh PP. Dalam visit bersama dan kegiatan interkolaborasi masih bergantung dengan PP.

Data ketenagaan keperawatan secara keseluruhan di RS X berjumlah1958 perawat, data tenaga keperawatan di unit A RS X berjumlah 602 perawat, dengan komposisi D3 78,7\% (474 perawat), Ners 19,8\% (119 perawat), S2 Keperawatan 1\% (6 perawat) dan di lantai 8 berjumlah 51 perawat, dengan komposisi D3 86,3\%(44 perawat), Ners 19,6\% (10 perawat). Gambaran komposisi D3 sangat dominan mencapai 70\%. Serta pendidikan berkelanjutan baik secara formal dan informal perlu diperhatikan terkait peningkatan kompetensi staf keperawatan terkait IPCP terutama teknik komunikasi. Survey dilakukan kepada perawat di ruang rawat inap dari 602 perawat didapatkan 108 orang perawat sebagai partisipan, yang terdiri dari 1 kepala ruang, 14 perawat primer, 2 perawat $\mathrm{PJ}$, dan 91 perawat asosiate.

Tabel. 1

KarakteristikPerawat Berdasarkan Demografi di Ruang Rawat Inap RS X Tahun 2021 (n: 108)

\begin{tabular}{|c|c|c|c|}
\hline Variabel & Kategori & $\mathrm{f}$ & $\%$ \\
\hline \multirow[t]{2}{*}{ Jenis kelamin } & Laki- laki & 10 & 9 \\
\hline & Perempuan & 98 & 91 \\
\hline \multirow[t]{5}{*}{ Usia } & $21-30$ Tahun & 47 & 44 \\
\hline & $31-40$ Tahun & 33 & 31 \\
\hline & $41-50$ Tahun & 19 & 17 \\
\hline & $51-60$ Tahun & 6 & 6 \\
\hline & 61-70 Tahun & 1 & 1 \\
\hline \multirow[t]{4}{*}{ Pendidikan } & D3 & 83 & 77 \\
\hline & S1 Ners & 23 & 21 \\
\hline & S2 Keperawatan & 1 & 1 \\
\hline & S2. Spesialis & 1 & 1 \\
\hline \multirow[t]{5}{*}{ Level Kompetensi } & PK I & 27 & 25 \\
\hline & PK II & 32 & 30 \\
\hline & PK III & 45 & 42 \\
\hline & PK IV & 4 & 4 \\
\hline & PK V & 0 & 0 \\
\hline \multirow[t]{4}{*}{ Jabatan } & Kepala Ruang & 1 & 1 \\
\hline & $\mathrm{PP}$ & 14 & 13 \\
\hline & $\mathrm{PJ}$ & 2 & 2 \\
\hline & PA & 91 & 84 \\
\hline
\end{tabular}

Berdasarkan Tabel 1 didapati hasil karakteristik responden survey kepuasan perawat dalam IPCP yang dilakukan saat identifikasi masalah adalah lebih banyak perawat yang berjenis kelamin perempuan $(91 \%)$ dari pada perawat laki-laki $(9,3 \%)$, usia responden terbayak adalah antara 21 - 30 tahun (44\%), dan usia 31 -40 tahun (33\%) atau usia produktif. Tingkat pendidikan terbanyak responden adalah D3 (83\%), yang kedua Ners (23\%). Level kompetensi responden untuk PK I (25\%), PK II (32\%), PK III (45\%) dan PK IV (4\%). Jabatan responden yang turut berpartisipasi dalam survey ini terbanyak adalah Perawat Asosiate (PA) sebesar 91\% dan Perawat Primer (PP) $14 \%$. 
Tabel. 2

Kepuasan Perawat pada Praktik Implementasi Interkolaborasi Professional dalam Asuhan Pasien Berdasarkan Kategori Tahun 2021 (n: 108)

\begin{tabular}{lccc}
\hline \multicolumn{1}{c}{ Variabel } & Kategori & $\mathrm{f}$ & $\%$ \\
\hline Kolaborasi & Sedang & 10 & 9 \\
& Tinggi & 98 & 91 \\
\hline Koordinasi & Sedang & 5 & 5 \\
& Tinggi & 103 & 95 \\
\hline Kerjasama & Sedang & 4 & 4 \\
& Tinggi & 104 & 96 \\
\hline Komunikasi & Sedang & 3 & 3 \\
& Tinggi & 105 & 97 \\
\hline Penghargaan & Sedang & 4 & 4 \\
& Tinggi & 104 & 96 \\
\hline Dukungan Organisasi & Sedang & 4 & 4 \\
& Tinggi & 104 & 96 \\
\hline
\end{tabular}

Berdasarkan tabel 2 didapati hasil kepuasan perawat dalam kolaborasi sudah tinggi (91\%), kepuasan dalam koordinasi sebesar 95\%, kepuasan dalam kerjasama dengan profesi lain 96\%, kepuasan dalam berkomunikasi 97\%, kepuasan mendapatkan penghargaan dalam IPCP 96\%, dan dukungan organisasi dalam praktik IPCP $96 \%$.

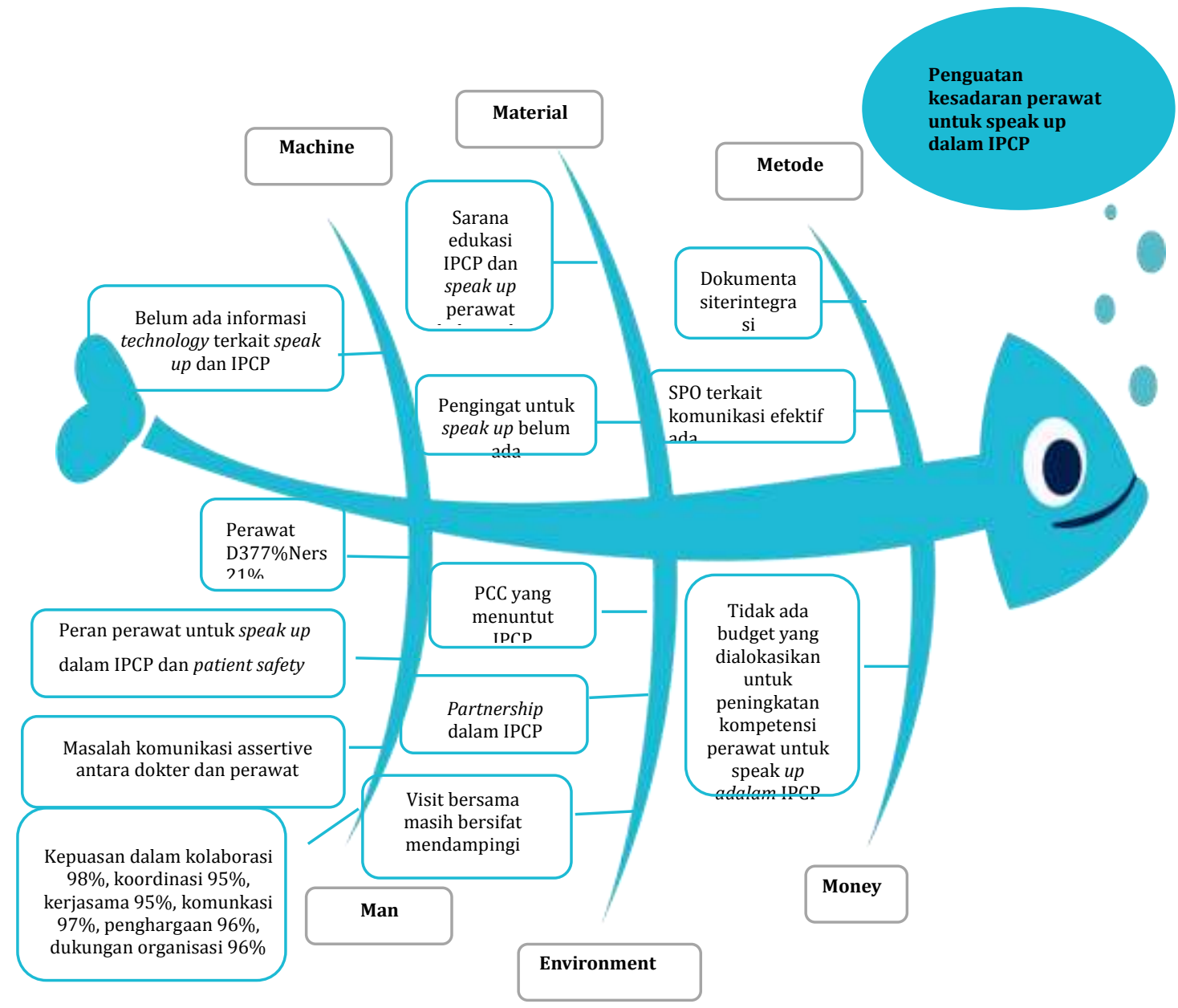

Gambar. 2

Fishbone 
Data hasil wawancara, observasi dan screening yang dianalisa dengan menggunakan fishbone (gambar 2) menunjukkan bahwa penguatan kesadaran perawat untuk speak up dalam IPCP perlu dioptimalkan.

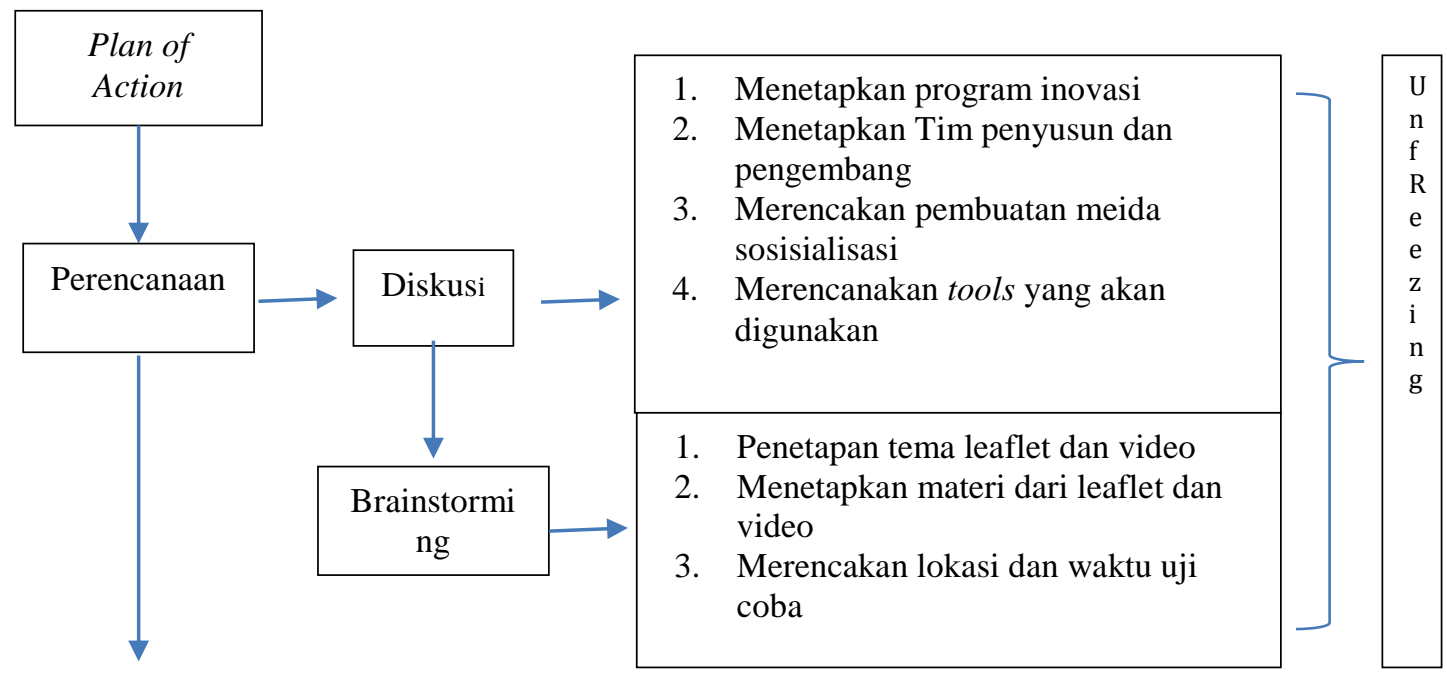

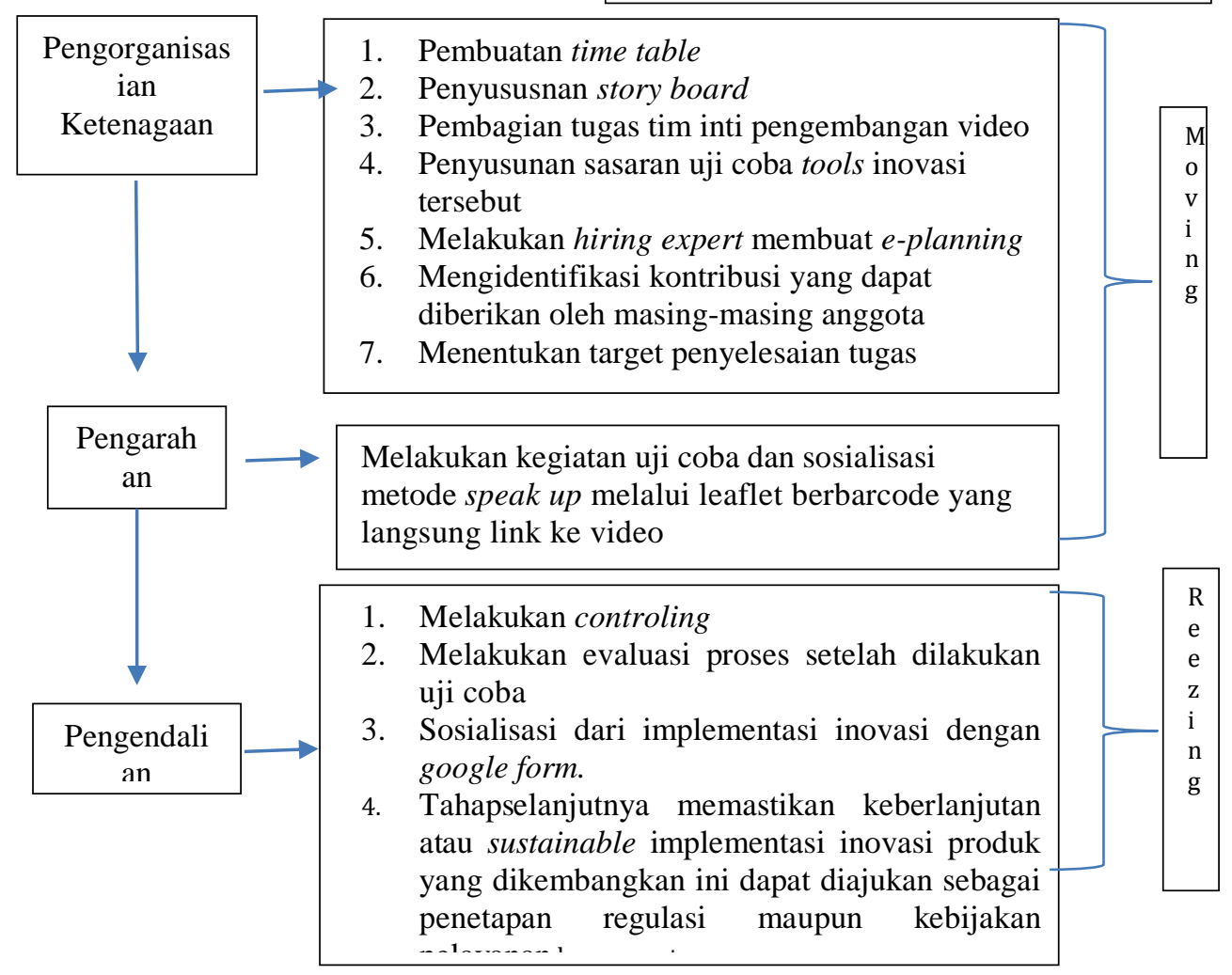

Evaluasi:

1. Produk Inovasi $\rightarrow$ Hasil evaluasi dari media video yang sudah di uji coba

2. Perawat $\rightarrow$ Hasil persepsi perawat terkait speak up dalam IPCP saat pre dan post melihat video metode speak up menunjukkan adanya peningkatan item jawaban yang diberikan. Peran perawat untuk speak up dalam IPCP dan patient safety

Gambar. 3

Plan of Action Program Speak Up untuk Perawat di RS X 


\section{EVALUASI}

Tahap evaluasi dilakukan dengan evaluasi uji coba tools pemantauan dan evaluasi persepsi perawat terkait IPCP dan evaluasi sebagai agen pembaharu dengan menilai produk inovasi yang dihasilkan yaitu video. Evaluasi dilakukan sebelum dan paska sosialisasi melalui instrumen dengan google form. Hasil uji coba tools yang pertama yaitu tools pemantauan dan evaluasi persepsi perawat terkait IPCP, saat pre dan post melihat video metode speak up menunjukkan adanya peningkatan item jawaban yang diberikan dan evalusi terkait kualitas video sebagai produk inovasi dengan cara menyebarkan instrument evaluasi dengan google form.

Hasil evaluasi dari media video yang sudah di uji coba terkait isi materi video sesuai dengan judul atau topik $66,7 \%$ sesuai dan $33,3 \%$ sangat sesuai, untuk materi yang disampaikan dalam video perawat berpendapat $77,8 \%$ bagus, $22,2 \%$ sangat bagus, alur cerita yang ada dalam video $100 \%$ bagus, video mudah dipahami $100 \%$, video bermanfaat $55,6 \%$ dan $44,4 \%$ sangat bermanfaat, ketajaman gambar $77,8 \%$ sesuai, caption $77,8 \%$ sesuai, kesesuaian warna $77,8 \%$ sesuai dan kesesuaian musik dan setting tempat dalam video $100 \%$ sesuai.

\section{PEMBAHASAN}

Pandemi COVID-19 memberi tantangan besar pada proses kolaborasi antara petugas kesehatan. Dalam penanganan pandemi setiap profesi kesehatan harus berkoordinasi dengan profesi lain untuk dapat memberikan layanan kesehatan yang aman dan berkualitas. Sehingga harus ada kondisi kerja yang kondusif dan aman secara interpersonal.Namun, tekanan kerja akibat perubahan pola kerja serta beban kerja yang tinggi mengakibatkan tingginya tingkat stress baik fisik maupun psikis. Akibatnya, secara tidak langsung, terbentuk atmosfer kerja yang tidak nyaman dan berimbas pada penurunan komunikasi assertive. Kondisi ini sangat beresiko menimbulkan konflik dalam kolaborasi interprofesi (Malawat et al., 2020).

Dari hasil identifikasi pengumpulan data dan menganalisa masalah terkait pelaksanaan praktik interkolaborasi antar profesi atau interprofessional collaboration practice didapatkan perlunya penguatan kesadaran perawat untuk speak up dalam IPCP menjadi sangat penting, karena dalam studi dalam the silent treatment yang menunjukkan bagaimana kegagalan perawat untuk speak up atau angkat bicara ketika diketahui ada resiko keselamatan. Ini juga berfokus pada tiga masalah khusus yang sering kali menghasilkan keputusan untuk tidak speak up atau angkat bicara, yaitu: jalan pintas yang berbahaya, tidak kompeten dan sikap tidak hormat atau disrespect (Fagan et al., 2021). Akibatnya, mereka sering gagal untuk menggunakan pengaruhnya dan pasien dirugikan (Kitson et al., 2019). Sedangkan perawat berada dalam posisi untuk mencegah banyak kesalahan dan meningkatkan outcome pasien, perawat melakukan speak up jika melihat sesuatu yang tidak aman, perawat ada di samping pasien dekat dengan masalah dan memiliki solusi kreatif.

Speak up penting untuk keselamatan pasien, tetapi profesional perawatan kesehatan sering ragu untuk menyuarakan keprihatinan mereka. Manajer keperawatan memiliki peran penting dalam mempengaruhi staf perawat untuk speak up $(\mathrm{Hu} \&$ Broome, 2020). Speak up mengacu pada peningkatan perhatian profesional perawatan kesehatan untuk kepentingan kualitas pelayanan dan keselamatan pasien (Palatnik, 2016). Ketika karyawan tidak angkat bicara tentang masalah, organisasi kehilangan kesempatan untuk peningkatan dan pembelajaran (Levine et al., 2020). 
Untuk itu organisasi perlu menghapus hambatan untuk speak up, seperti adanya stereotip, sebab ada hubungan antara stereotip dan praktek kolaboratif antar profesional, dan stereotip berbeda di kalangan profesional kesehatan itu akan menyebabkan kesulitan dalam praktik kolaboratif di rumah sakit (Cole et al., 2019; Sari et al., 2018). Dimana penelitian menunjukkan bahwa kegagalan untuk speak up tidak terbatas pada pekerjaan tertentu tetapi terjadi lintas pekerjaan, termasuk kekhawatiran tentang status hierarki yang memimpin beberapa profesional perawatan kesehatan, yang mempertanyakan kemampuan mereka untuk berbicara, tetapi perawat lebih mungkin merasakan kemampuan berbicara setelah menerima intervensi pendidikan tentang speak up (Levine et al., 2020).

Sebagai advokat, perawat yang mengambil tindakan untuk berbicara untuk pasien mereka memiliki identitas diri yang positif dan merasa aman serta bertanggungjawab kepada pasien mereka. Sebaliknya, seperti kelompok tertindas perawat menjadi putus asa untuk berbicara saat mengalami tekanan sosial atau ketika mereka kurang percaya diri. Perbedaan generasi juga memengaruhi cara perawat berkomunikasi pada saat observasi tampak bahwa speak up bukan sebuah budaya yang nyaman dilakukan oleh perawat, orang Asia memiliki keraguan untuk menyuarakan apa yang didapatkannya (Lee et al., 2021; Etchegaray et al., 2020).

Selain itu Perubahan nilai dari service oriented menjadi pendekatan patient centred collaborative ini dibutuhkan dalam organisasi kesehatan untuk melaksanakan kolaborasi interprofesional dalam praktik yang berpusat pada pasien (Hijazi et al., 2018; James-Scotter et al., 2019). Sebuah penelitian menunjukkan bahwa transisi tersebut membutuhkan upaya besar dari profesional perawatan kesehatan (Hijazi et al., 2018; James-Scotter et al., 2019; Naldemirci et al., 2017). Perawat sebagai leader dalam IPCP, masih belum mampu menggunakan kemampuannya dengan baik, apalagi dengan adanya stereotipe yang menempatkan perawat pada posisi kedua dari pada dokter (Sari et al., 2018; Tang et al., 2018). Perawat harus memiliki kepercayaan diri dalam membagikan informasi dan pengetahuannya, agar dapat terlibat aktif dalam IPCP (Chew et al., 2019; Papermaster \& Champion, 2020; Sari et al., 2018). Perawat memiliki critical thingking dan evidence based practice perawat serta merupakan advokat pertama dan terdepan bagi pasien, selain itu perawat juga sebagai pemberi asuhan, komunikator, pendidik, advokat klien, konselor, agen pembaharu, pemimpin, manajer, manajer kasus, pengembangan karir keperawatan. Untuk itu kita sebagai perawat harus percaya diri untuk speak up (Skaggs et al., 2018).

Upaya penguatan kesadaran perawat untuk speak up dalam IPCP dilakukan pilot project dengan menyiapkan informasi technology terkait speak up dan sarana edukasi IPCP dan speak up yang belum tersedia, tentu saja keberhasilan dari pilot project ini sangat tergantung dari bagaimana budaya organisasi yang mendukung praktik interkolaborasi, baik itu dukungan dari low manager sampai dengan top manager, seperti pada studi ini menunjukkan bahwa budaya caring adalah esensi dari kolaborasi interprofesional karena itu membangun suasana yang memenuhi kebutuhan dasar anggota tim dan mengikat profesional perawatan kesehatan bersama-sama (Wei et al., 2020). Penelitian lain juga menunjukkan bahwa budaya peduli dalam perawatan kesehatan dapat membawa hasil yang positifuntuk pasien dan profesional perawatan kesehatan (Watson et al., 2018; Wei et al., 2019, 2020). Dibutuhkan pemimpin yang mendukung dan mengarahkan stafnya untuk kolaborasi interprofesional, dengan menyediakan pelatihan dan pembinaan profesional kesehatan dan pekerja sehingga 
mereka lebih siap untuk dan bekerja lebih efektif dalam praktik kolaboratif interprofesional (Folkman et al., 2019; Hu \& Broome, 2020).

Pada pilot study speak up pada perawat di ruang rawat inap dalam rangka meningkatkan kesadaran perawat untuk melakukan speak up dalam IPCP dengan menggunakan leaflet dan video yang dilakukan di RS X berjalan dengan baik. Dimana isi dari leaflet dan video itu antara lain: latar belakang dan definisi IPCP, pengertian speak up,kenapa perawat harus speak up, masalah apa yang perlu untuk di speak up, dan kenapa speak up penting untuk keselamatan pasien. Hasil uji persepsi perawat mengenai IPCP meningkat setelah dilakukan sosialisasi. Peningkatan persepsi dan pemahaman perawat tentang IPCP menjadi hal yang penting, agar perawat dapat menjalankan perannya dalam IPCP dengan baik, serta jumlah perawat yang besar dalam pelayanan membuat perawat memiliki peranan penting dalam pelaksanaan IPCP. Sebab perawat memiliki persentase terbesar dalam sebuah tim asuhan pasien (57\%), sehingga perawatlah yang harus menjadi leader dalam menginisiasi pelaksanaan IPCP terutama perawat klinis (Papermaster \& Champion, 2020). Perawat perlu mengumpulkan setiap sumber untuk memperkuat pengambilan keputusan dalam pemberian asuhan termasuk dengan berkoordinasi dengan semua profesi, yang akan berdampak pada peningkatan keterampilan perawat dan juga proses pemulihan pasien (Schot et al., 2020).

Pemberdayaan perawat untuk speak up sangat diperlukan, dengan menggunakan inovasi selama pandemi ini. Memberdayakan perawat dan supervisor dapat meningkatkan budaya keselamatan pasien secara keseluruhan. Keterbukaan komunikasi, handoff dan transisi, kerja tim dalam unit, pembelajaran dan peningkatan berkelanjutan, ekspektasi manajer dan tindakan yang mempromosikan keselamatan pasien meningkat secara signifikan setelah intervensi. Oleh karena itu, program ini dapat dimanfaatkan untuk mempromosikan dimensi penting dari budaya keselamatan pasien ini (Amiri et al., 2018).

\section{SIMPULAN}

Pilot project ini dilakukan untuk mengidentifikasi dan menganalisa masalah terkait pelaksanaan praktik interkolaborasi antar profesi atau interprofessional collaboration practice, gambaran tentang persepsi kepuasan perawat dalam kolaborasi sudah tinggi, kepuasan dalam koordinasi sebesar 95\%, kepuasan dalam kerjasama dengan profesi lain 96\%, kepuasan dalam berkomunikasi 97\%, kepuasan mendapatkan penghargaan dalam IPCP 96\%, dan dukungan organisasi dalam praktik IPCP $96 \%$. Namun data dari hasil wawancara, observasi dan screening yang dianalisa dengan menggunakan fishbone menunjukkan bahwa penguatan kesadaran perawat untuk speak up dalam IPCP perlu dioptimalkan, dengan demikian untuk meningkatkan kesadaran perawat untuk speak up dibuatlah produk inovasi dan dilakukan sosialisasi serta evaluasi.

\section{SARAN}

Dilakukan penelitian lebih lanjut mengenai faktor yang mempengaruhi kesadaran perawat untuk speak up dalam IPCP, dan peningkatan peran dan fungsi manajer keperawatan dalam peningkatan kesadaran perawat untuk speak up. 


\section{DAFTAR PUSTAKA}

Alingh, C. W., Van-Wijngaarden, J. D. H., Van De Voorde, K., Paauwe, J., \& Huijsman, R. (2019). Speaking Up about Patient Safety Concerns: The Influence of Safety Management Approaches and Climate on Nurses' Willingness to Speak Up. BMJ Quality \& Safety, 28(1), 39-48. https://doi.org/10.1136/bmjqs-2017007163

Amadi, R. H. (2020). Improving Interprofessional Collaboration Between Physicians and Nurse Practitioners in Virtual Primary Care Telehealth Through CoManagement Education (Issue August) [Texas A\&M University]. https://hdl.handle.net/1969.6/89080

Amiri, M., Khademian, Z., \& Nikandish, R. (2018). The Effect of Nurse Empowerment Educational Program on Patient Safety Culture: A Randomized Controlled Trial. BMC Medical Education, 18(1), 1-8. https://doi.org/10.1186/s12909-018-1255-6

Baik, D., \& Zierler, B. (2019). RN Job Satisfaction and Retention After an Interprofessional Team Intervention. Western Journal of Nursing Research. https://doi.org/10.1177/0193945918770815

Bursiek, A. A., Hopkins, M. R., Breitkopf, D. M., Grubbs, P. L., Joswiak, M. E., Klipfel, J. M., \& Johnson, K. M. (2020). Use of High-Fidelity Simulation to Enhance Interdisciplinary Collaboration and Reduce Patient Falls. Journal of Patient Safety, 16(3), 245-250. https://doi.org/10.1097/PTS.0000000000000277

Chew, B. H., Tang, C. J., Lim, W. S., Yap, J. K. Y., Zhou, W., \& Liaw, S. Y. (2019). Interprofessional Bedside Rounds: Nurse-Physician Collaboration and Perceived Barriers in an Asian Hospital. Journal of Interprofessional Care, 33(6), 820-822. https://doi.org/10.1080/13561820.2019.1566218

Cole, D. A., Bersick, E., Skarbek, A., Cummins, K., Dugan, K., \& Grantoza, R. (2019). The Courage to Speak Out: A Study Describing Nurses' Attitudes to Report Unsafe Practices in Patient Care. Journal of Nursing Management, 27(6), 11761181. https://doi.org/10.1111/jonm.12789

Edgman-Levitan, S., \& Schoenbaum, S. C. (2021). Patient-Centered Care: Achieving Higher Quality by Designing Care Through the Patient's Eyes. Israel Journal of Health Policy Research, 10(1), 1-5. https://doi.org/10.1186/s13584-021-00459-9

Etchegaray, J. M., Ottosen, M. J., Dancsak, T., \& Thomas, E. J. (2020). Barriers to Speaking Up About Patient Safety Concerns. Journal of Patient Safety, 16(4), e230-e234. https://doi.org/10.1097/PTS.0000000000000334

Fagan, A., Lea, J., \& Parker, V. (2021). Conflict, Confusion and Inconsistencies: PreRegistration Nursing Students' Perceptions and Experiences of Speaking Up for Patient Safety. Nursing Inquiry, 28(1). https://doi.org/10.1111/nin.12381

Faridah, I., Setyowati, S., Lestari, F., \& Hariyati, R. T. S. (2021). The Correlation Between Work Environment and Patient Safety in a General Hospital in Indonesia. Enfermería Clínica, 31, S220-S224. https://doi.org/10.1016/j.enfcli.2020.12.026

Folkman, A. K., Tveit, B., \& Sverdrup, S. (2019). Leadership in Interprofessional Collaboration in Health Care. Journal of Multidisciplinary Healthcare, Volume 12, 97-107. https://doi.org/10.2147/JMDH.S189199

Gunawan, D., \& Hariyati, T. S. R. (2019). The Implementation of Patient Safety Culture in Nursing Practice. Enfermería Clínica, 29, 139-145. https://doi.org/10.1016/j.enfcli.2019.05.007 
Hijazi, H. H., Harvey, H. L., Alyahya, M. S., Alshraideh, H. A., Al Abdi, R. M., \& Parahoo, S. K. (2018). The Impact of Applying Quality Management Practices on Patient Centeredness in Jordanian Public Hospitals: Results of Predictive Modeling. Inquiry (United States), 55. https://doi.org/10.1177/0046958018754739

Hu, Y., \& Broome, M. (2020). Leadership Characteristics for Interprofessional Collaboration in China. Journal of Professional Nursing, 36(5), 356-363. https://doi.org/10.1016/j.profnurs.2020.02.008

James-Scotter, M., Walker, C., \& Jacobs, S. (2019). An Interprofessional Perspective on Job Satisfaction in the Operating Room: A Review of The Literature. Journal of Interprofessional Care, 33(6), 782-794. https://doi.org/10.1080/13561820.2019.1593118

Kitson, A., Carr, D., Conroy, T., Feo, R., Grønkjær, M., Huisman-de Waal, G., Jackson, D., Jeffs, L., Merkley, J., Muntlin Athlin, A., Parr, J., Richards, D. A., Sørensen, E. E., \& Wengström, Y. (2019). Speaking Up for Fundamental Care: The ILC Aalborg Statement. BMJ Open, 9(12), e033077. https://doi.org/10.1136/bmjopen2019-033077

Lee, S. E., Choi, J., Lee, H., Sang, S., Lee, H., \& Hong, H. C. (2021). Factors Influencing Nurses' Willingness to Speak Up Regarding Patient Safety in East Asia: A Systematic Review. Risk Management and Healthcare Policy, 14, 10531063. https://doi.org/10.2147/RMHP.S297349

Levine, K. J., Carmody, M., \& Silk, K. J. (2020). The Influence of Organizational Culture, Climate and Commitment on Speaking Up about Medical Errors. Journal of Nursing Management, 28(1), 130-138. https://doi.org/10.1111/jonm.12906

Malawat, K. Y., Hariyati, R. T. S., \& Sari, K. M. (2020). Nursing Managers' Strategies for Reducing Interpersonal and Interprofessional Conflicts in the COVID-19 Pandemic. International Journal of Nursing and Health Services (IJNHS), 3(6), 716-721. https://doi.org/10.35654/ijnhs.v3i6.403

Mawarni, E., Dachriyanus, D., Maisa, E. A., \& Fajri, J. Al. (2019). Gambaran Pengetahuan Inter Professional Collaboration pada Profesional Pemberi Asuhan di Rumah Sakit Khusus Propinsi Jambi: Kajian. Jurnal Ilmiah Universitas Batanghari Jambi, 19(2), 416. https://doi.org/10.33087/jiubj.v19i2.676

Moll, A., Lambert, S., Visker, J., Dunseith, N., Wang, A., Azim, S., \& Cox, C. C. (2019). A Case Study Activity to Assess Nursing Students' Perceptions of Their Interprofessional Healthcare Team's Collaborative Decision-Making Process. Journal of Interprofessional Education \& Practice, 14, 18-21. https://doi.org/10.1016/j.xjep.2018.11.005

Naldemirci, Ö., Wolf, A., Elam, M., Lydahl, D., Moore, L., \& Britten, N. (2017). Deliberate and Emergent Strategies for Implementing Person-Centred Care: A Qualitative Interview Study with Researchers, Professionals and Patients. BMC Health Services Research, 17(1), 1-10. https://doi.org/10.1186/s12913-017-24702

Orchard, C., Pederson, L. L., Read, E., Mahler, C., \& Laschinger, H. (2018). Assessment of Inter Professional Team Collaboration Scale (AITCS): Further Testing and Instrument Revision. Journal of Continuing Education in the Health Professions, 38(1), 11-18. https://doi.org/10.1097/CEH.0000000000000193

Palatnik, A. M. (2016). Speak Up for Patient Safety. In Nursing Critical Care. https://doi.org/10.1097/01.CCN.0000503425.05594.02 
Papermaster, A. E., \& Champion, J. D. (2020). Exploring the Use of Curbside Consultations for Interprofessional Collaboration and Clinical Decision-Making. Journal of Interprofessional Care, 00(00), 1-8. https://doi.org/10.1080/13561820.2020.1768057

Ridar, I., \& Santoso, A. (2018). Peningkatkan Komunikasi dalam Pelaksanaan Interprofessional Collaboration melalui Catatan Perkembangan Pasien Terintegrasi. Prosiding Seminar Nasional Unimus. https://prosiding.unimus.ac.id/index.php/semnas/article/view/114

Rousseau, C., Pontbriand, A., Nadeau, L., \& Johnson-Lafleur, J. (2017). Perception of Interprofessional Collaboration and Co-Location. J Can Acad Child Adolesc Psychiatry, 26(27 juni 2017), 198-204. https://www.lib.uwo.ca/cgibin/ezpauthn.cgi?url=http://search.proquest.com/docview/1971766308?accountid $=15115 \% 0$ Ahttps://ocul-

uwo.primo.exlibrisgroup.com/openurl/01OCUL_UWO/01OCUL_UWO:UWO_D EFAULT??url_ver=Z39.88-2004\&rft_val_fmt=info:ofi/fmt:kev:mtx:journa

Sari, R. V., Hariyati, R. T. S., \& Syuhaimie, H. A. Y. (2018). The Association Between Stereotyping and Interprofessional Collaborative Practice. Enfermeria Clinica, 28, 134-138. https://doi.org/10.1016/S1130-8621(18)30053-6

Schot, E., Tummers, L., \& Noordegraaf, M. (2020). Working on Working Together. A Systematic Review on How Healthcare Professionals Contribute to Interprofessional collaboration. Journal of Interprofessional Care, 34(3), 332342. https://doi.org/10.1080/13561820.2019.1636007

Skaggs, M. K. D., Daniels, J. F., Hodge, A. J., \& DeCamp, V. L. (2018). Using the Evidence-Based Practice Service Nursing Bundle to Increase Patient Satisfaction. Journal of Emergency Nursing, 44(1), 37-45. https://doi.org/10.1016/j.jen.2017.10.011

Tang, C. J., Zhou, W. T., Chan, S. W. C., \& Liaw, S. Y. (2018). Interprofessional Collaboration between Junior Doctors and Nurses in the General Ward Setting: A Qualitative Exploratory Study. Journal of Nursing Management, 26(1), 11-18. https://doi.org/10.1111/jonm.12503

Verd-Aulí, X., Maqueda-Palau, M., \& Miró-Bonet, M. (2021). Colaboración Interprofesional en Las Sesiones Clínicas Conjuntas en Una UNIDAD de Cuidados Intensivos: Percepciones de Enfermeras y Médicos. Enfermería Intensiva, 32(1), 3-10. https://doi.org/10.1016/j.enfi.2020.02.004

Vittadello, F., Mischo-Kelling, M., Wieser, H., Cavada, L., Lochner, L., Naletto, C., Fink, V., \& Reeves, S. (2018). A Multiple-Group Measurement Scale for Interprofessional Collaboration: Adaptation and Validation Into Italian and German Languages. Journal of Interprofessional Care, 32(3), 266-273. https://doi.org/10.1080/13561820.2017.1396298

Watson, J., Porter-O'Grady, T., Horton-Deutsch, S., \& Malloch, K. (2018). Quantum Caring Leadership: Integrating Quantum Leadership With Caring Science. Nursing Science Quarterly, 31(3), 253-258. https://doi.org/10.1177/0894318418774893

Wei, H., Corbett, R. W., Ray, J., \& Wei, T. L. (2020). A Culture of Caring: The essence Of Healthcare Interprofessional Collaboration. Journal of Interprofessional Care, 34(3), 324-331. https://doi.org/10.1080/13561820.2019.1641476 
Wei, H., Fazzone, P. A., Sitzman, K., \& Hardin, S. R. (2019). The Current Intervention Studies Based on Watson's Theory of Human Caring: A Systematic Review. International Journal for Human Caring, 23(1), 4-22. https://doi.org/10.20467/1091-5710.23.1.4

World Health Organisation. (2017). WHO Strategic Communications Framework. World Health Organization, 2017(July), 56

Yusra, R. Y., Findyartini, A., \& Soemantri, D. (2019). Healthcare Professionals' Perceptions Regarding Interprofessional Collaborative Practice In Indonesia. Journal of Interprofessional Education and Practice, 15(September 2018), 24-29. https://doi.org/10.1016/j.xjep.2019.01.005 